\title{
Plasma-free nitrogen doping and homojunction light-emitting diodes based on $\mathrm{ZnO}$
}

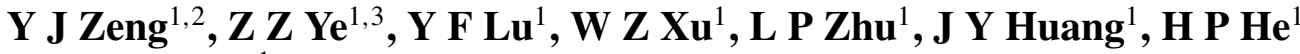 \\ and $\mathrm{B}$ H Zhao ${ }^{1}$ \\ ${ }^{1}$ State Key Laboratory of Silicon Materials, Zhejiang University, Hangzhou 310027, \\ People's Republic of China \\ ${ }^{2}$ Solid-state Physics and Magnetism Section, Department of Physics and Astronomy, Katholieke \\ Universiteit Leuven, Celestijnenlaan 200 D, BE-3001 Leuven, Belgium \\ E-mail: yezz@zju.edu.cn and huang@zju.edu.cn
}

Received 20 May 2008, in final form 16 June 2008

Published 25 July 2008

Online at stacks.iop.org/JPhysD/41/165104

\begin{abstract}
The authors develop a plasma-free metalorganic chemical vapour deposition method to grow $\mathrm{N}$-doped p-type $\mathrm{ZnO}$ films. The incorporation of the $\mathrm{N}$ acceptor and the corresponding change in the Fermi level are well confirmed by x-ray photoelectron spectroscopy.

Temperature-dependent photoluminescence reveals the acceptor-related emissions, namely, neutral acceptor-bound exciton and probably donor-acceptor pair transition. In addition, typical rectifying $I-V$ characteristics and room-temperature electroluminescence from $\mathrm{ZnO}$ homojunction light-emitting diodes are demonstrated.
\end{abstract}

(Some figures in this article are in colour only in the electronic version)

\section{Introduction}

$\mathrm{ZnO}$, with a large exciton binding energy of $60 \mathrm{meV}$, is presently receiving worldwide attention because of its advantages for blue/ultraviolet (UV) light emitters and detectors [1-3]. Nominally undoped $\mathrm{ZnO}$ typically exhibits n-type conductivity, which has been ascribed to various mechanisms including native defects and/or interstitial hydrogen [4-6]. The realization of p-type material, however, has been proven difficult due to its asymmetric doping limitations [7]. Fortunately, in virtue of the considerable worldwide efforts, various elements have been investigated as the p-type dopants for $\mathrm{ZnO}$, such as $\mathrm{N}$ [8-10], P [11, 12], As [13], $\mathrm{Sb}$ [14] and $\mathrm{Li}[15,16]$. In particular, recent progress in $\mathrm{ZnO}$ homojunction light-emitting diodes (LEDs) has made the potentials of $\mathrm{ZnO}$ more feasible [11, 17-25].

Considering all the p-type dopants and the limited reports on $\mathrm{ZnO}$ homojunction LEDs, $\mathrm{N}$ with a similar ionic radii as $\mathrm{O}$ appears to be promising. Generally, due to the low solubility of $\mathrm{N}$, generating activated $\mathrm{N}$ by a plasma-assisted process is required for effective $\mathrm{N}$ doping in $\mathrm{ZnO}$, independently

\footnotetext{
3 Author to whom any correspondence should be addressed.
}

of the adopted $\mathrm{N}$ sources [8,10,17-19,25]. On the other hand, much less attention has been focused on plasma-free $\mathrm{N}$ doping in $\mathrm{ZnO}$. The plasma-assisted growth, however, needs a relatively rigorous pressure condition, which is not favoured for the growth of a p-type $\mathrm{ZnMgO}$ barrier layer as well as mass production. In this study, we develop a plasma-free metalorganic chemical vapour deposition (MOCVD) method to grow $\mathrm{N}$-doped p-type $\mathrm{ZnO}$ films. Room-temperature electroluminescence (EL) from the $\mathrm{ZnO}$ homojunction LEDs is demonstrated.

\section{Experimental details}

$\mathrm{N}$-doped $\mathrm{ZnO}$ films were grown by a low-pressure plasmafree MOCVD method. $c$-plane (0001) sapphire and n-type bulk $\mathrm{ZnO}$ were used as the substrates. Diethyl zinc was used as the zinc source. A mixture of $\mathrm{O}_{2}$ and $\mathrm{NO}$ was employed as both the oxygen source and the $\mathrm{N}$ doping source. The growth temperature was $400^{\circ} \mathrm{C}$ and the chamber pressure was maintained at $20 \mathrm{~Pa}$ during the growth process. Hall-effect measurements were carried out in the van der Pauw configuration (Bio-Rad HL5500PC) 
Table 1. Electrical properties of $\mathrm{N}$-doped $\mathrm{ZnO}$ films grown on sapphire substrates.

\begin{tabular}{lllll}
\hline $\begin{array}{l}\text { NO flow } \\
(\mathrm{sccm})\end{array}$ & $\begin{array}{l}\text { Resistivity } \\
(\Omega \mathrm{cm})\end{array}$ & $\begin{array}{l}\text { Hall mobility } \\
\left(\mathrm{cm}^{2} \mathrm{~V}^{-1} \mathrm{~s}^{-1}\right)\end{array}$ & $\begin{array}{l}\text { Carrier } \\
\text { concentration }\left(\mathrm{cm}^{-3}\right)\end{array}$ & $\begin{array}{l}\text { Carrier } \\
\text { type }\end{array}$ \\
\hline 10 & 25.9 & 3.83 & $6.25 \times 10^{16}$ & $40 \% \mathrm{p}$ \\
13 & 16.3 & 3.27 & $1.16 \times 10^{17}$ & $\mathrm{p}$ \\
15 & 43.2 & 1.45 & $9.92 \times 10^{16}$ & $85 \% \mathrm{p}$ \\
18 & 96.6 & 0.354 & $1.83 \times 10^{17}$ & $60 \% \mathrm{p}$ \\
\hline
\end{tabular}

at room temperature. The chemical states of the doped $\mathrm{N}$ and the position of the Fermi level with respect to the valence band maximum (VBM) were analysed by $\mathrm{x}$-ray photoelectron spectroscopy (XPS Thermo ESCALAB 250, Al $\mathrm{K} \alpha$ radiation source $h v=1486.6 \mathrm{eV})$. Temperaturedependent photoluminescence (PL) measurements were performed using an $\mathrm{He}-\mathrm{Cd} 325 \mathrm{~nm}$ laser as the excitation source. $\mathrm{ZnO} \mathrm{p}-\mathrm{n}$ homojunction LEDs were fabricated by the deposition of an N-doped p-type layer on an n-type bulk ZnO substrate. Au and In-Zn alloys were used as the ohmic contact electrodes for the $\mathrm{p}$ side and the $\mathrm{n}$ side, respectively.

\section{Results and discussion}

Table 1 summarizes the results of Hall-effect measurements on the $\mathrm{N}$-doped $\mathrm{ZnO}$ films grown on the sapphire substrates. The typical thickness of the $\mathrm{N}$-doped $\mathrm{ZnO}$ layer is around $400 \mathrm{~nm}$. It can be seen that stable p-type conductivity is obtained with a proper flow of NO $(13 \mathrm{sccm}$ (standard cubic centimetres per minute)). The optimal results include a resistivity of $16.3 \Omega \mathrm{cm}$, a Hall mobility of $3.27 \mathrm{~cm}^{2} \mathrm{~V}^{-1} \mathrm{~s}^{-1}$ and a hole concentration of $1.16 \times 10^{17} \mathrm{~cm}^{-3}$. It is theoretically predicted that the formation energy of the $\mathrm{N}_{O}$ acceptor will decrease when NO is used as the $\mathrm{N}$ doping source [26]. By deliberately adjusting the NO flow, we are able to achieve stable p-type conductivity. Therefore, our experimental results support the theoretical calculation that NO would be a good p-type dopant for $\mathrm{ZnO}$ [26]. However, increasing or decreasing the NO flow results in the instability of the carrier type, as shown in table 1. When the NO flow is as low as $10 \mathrm{sccm}$, the concentration of the $\mathrm{N}_{\mathrm{O}}$ acceptor is insufficient to compensate for the background donor. On the other hand, when the NO flow increases to 15 or $18 \mathrm{sccm}$, the formation of the $\left(\mathrm{N}_{2}\right)_{\mathrm{O}}$ donor will be energetically favoured [26], serving as the compensating centre for the $\mathrm{N}_{O}$ acceptor. It is believed that both cases become the limitation for the $\mathrm{N}$ acceptor doping in $\mathrm{ZnO}$, which are probably responsible for the observed instability of the carrier type. The conductivity on the bulk $\mathrm{ZnO}$ substrates, however, is unavailable due to the possible influence of the conducting substrates.

The chemical state of the doped $\mathrm{N}$ in the $\mathrm{ZnO}$ layer grown on the bulk ZnO was analysed by XPS. Figure 1 illustrates the $\mathrm{N}$ $1 \mathrm{~s}$ core level narrow scan spectrum. A peak at around $398.2 \mathrm{eV}$, attributed to $\mathrm{Zn}-\mathrm{N}$ bonding [27], is observed. Additionally, the mole concentration of $\mathrm{N}$ is calculated to be $1.3 \%$ according to its integrated intensity and sensitivity factor. Therefore, it is confirmed that the $\mathrm{N}$ acceptor is introduced into the $\mathrm{ZnO}$ matrix, without the plasma-assisted process.

It is well known that the Fermi level of a semiconductor will shift up/down in energy due to donor/acceptor doping. In

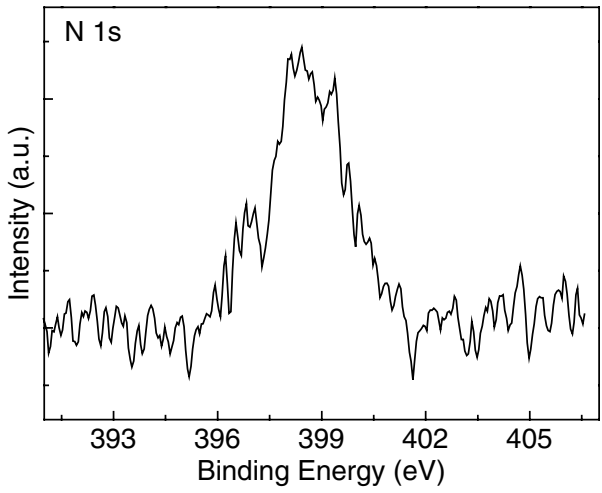

Figure 1. An XPS narrow scan spectrum of the N 1s core level for $\mathrm{N}$-doped $\mathrm{ZnO}$ films grown on the bulk $\mathrm{ZnO}$ substrate.

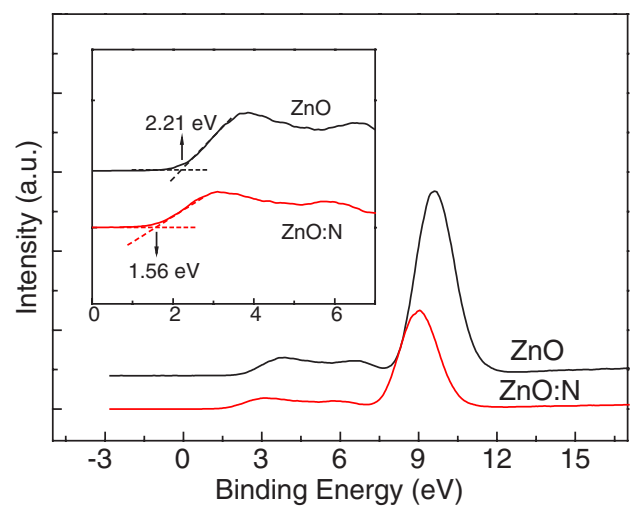

Figure 2. VB XPS spectra for nominally undoped and N-doped $\mathrm{ZnO}$ films grown on the bulk $\mathrm{ZnO}$ substrate. The inset shows $\mathrm{VB}$ spectra near the Fermi level.

this regard, valence band (VB) XPS spectra were provided to investigate the $\mathrm{N}$-acceptor doping effects. Figure 2 compares the VB XPS spectra of the nominally undoped and N-doped $\mathrm{ZnO}$ films grown on the bulk $\mathrm{ZnO}$ substrates. The features at $9.6 \mathrm{eV}, 6.5 \mathrm{eV}$ and $3.7 \mathrm{eV}$ for the undoped one are known to stem from $\mathrm{Zn} 3 \mathrm{~d}$, mixed $\mathrm{Zn} 4 \mathrm{~s}-\mathrm{O} 2 \mathrm{p}$ and $\mathrm{O} 2 \mathrm{p}$ states, respectively $[28,29]$. To better elucidate the $\mathrm{N}$ doping effects, the inset of figure 2 shows the VB spectra near the Fermi level. By extrapolating the leading edge of the $\mathrm{O} 2 \mathrm{p}$-derived $\mathrm{VB}$ to its intersection with background counts near the Fermi level, the position of the Fermi level with respect to the VBM can be determined. The nominally undoped $\mathrm{ZnO}$ shows a Fermi level located at $2.21 \mathrm{eV}$ above the VBM. Considering the band gap of $3.37 \mathrm{eV}$ at room temperature, this Fermi level is near the middle of the band gap rather than the conduction band minimum (CBM). The location of the Fermi level suggests a low background electron concentration, which will favour the 

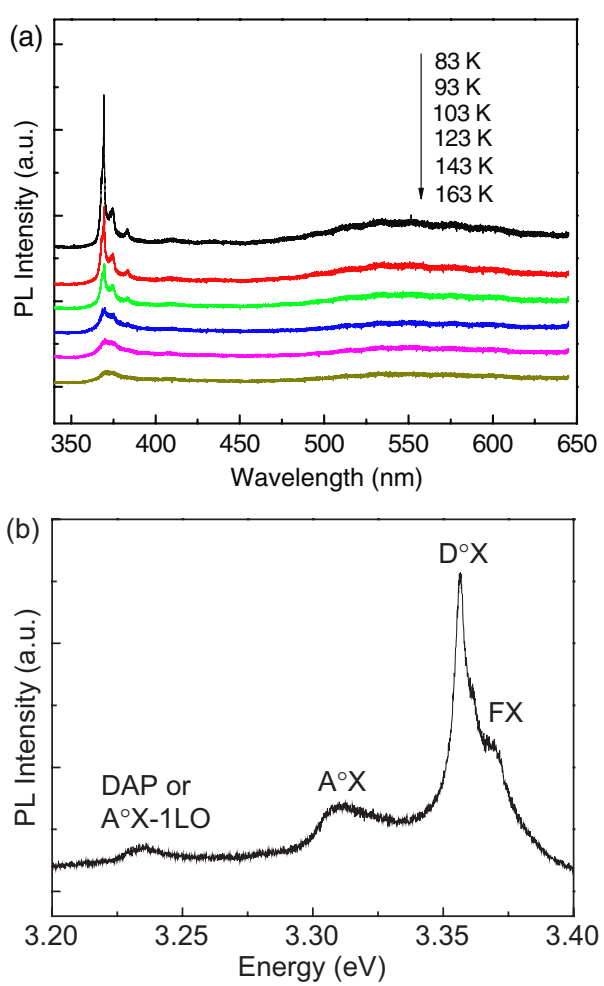

Figure 3. (a) Temperature-dependent PL spectra of the N-doped $\mathrm{ZnO}$ film grown on the bulk $\mathrm{ZnO}$ substrate. (b) The UV region of the PL spectrum at $83 \mathrm{~K}$.

p-type doping. The Fermi level of the $\mathrm{N}$-doped $\mathrm{ZnO}$ shifts down towards the VBM by $650 \mathrm{meV}$ in comparison with the undoped one, which offers the evidence for $\mathrm{N}$-acceptor doping in view of the energy band. Furthermore, the Fermi level below the middle of the band gap, in principle, indicates a p-type behaviour, which was unavailable in the previous Hall-effect measurements.

Figure 3(a) shows temperature-dependent PL spectra of the $\mathrm{N}$-doped $\mathrm{ZnO}$ films grown on the bulk $\mathrm{ZnO}$ substrates. The thickness of the N-doped layer is around $800 \mathrm{~nm}$, which is much larger than the typical penetration depth of the $325 \mathrm{~nm}$ laser in $\mathrm{ZnO}$. Thus, it is assured that the collected PL signal comes from the $\mathrm{N}$-doped layer rather than the bulk $\mathrm{ZnO}$ substrate. The PL spectra are characterized by several resolved near-band-edge (NBE) emissions with a weak deep band, indicating a high optical quality.

To better assign the NBE PL peaks, the UV region of the PL spectrum at $83 \mathrm{~K}$ is illustrated in figure $3(b)$. The peaks at $3.368 \mathrm{eV}, 3.356 \mathrm{eV}$ and $3.311 \mathrm{eV}$ are tentatively assigned to free exciton (FX), neutral donor-bound exciton $\left(\mathrm{D}^{\circ} \mathrm{X}\right)[30]$ and neutral acceptor-bound exciton $\left(\mathrm{A}^{\circ} \mathrm{X}\right)$ [8], respectively. The $3.236 \mathrm{eV}$ emission might be donor-acceptor pair transition (DAP) or the longitudinal-optical phonon replica of $\mathrm{A}^{\circ} \mathrm{X}$. As evident in figure $3(a)$, the intensity of $\mathrm{D}^{\circ} \mathrm{X}$ as well as of $\mathrm{A}^{\circ} \mathrm{X}$ decreases significantly with the increased temperature and is eventually buried by the FX emission at around $150 \mathrm{~K}$, showing the typical characteristics of the bound exciton. The observations of obvious acceptor-related transitions, such as $\mathrm{A}^{\circ} \mathrm{X}$ and probably DAP, indicate the presence of an acceptor state in the $\mathrm{N}$-doped layer, which is probably associated with

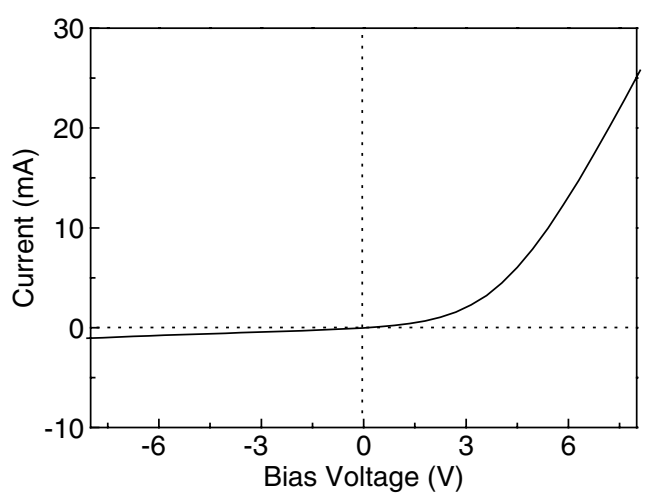

Figure 4. $I-V$ characteristics of the $\mathrm{ZnO} \mathrm{p}-\mathrm{n}$ homojunction, consisting of an $\mathrm{N}$-doped p-type layer and an n-type bulk $\mathrm{ZnO}$ substrate.

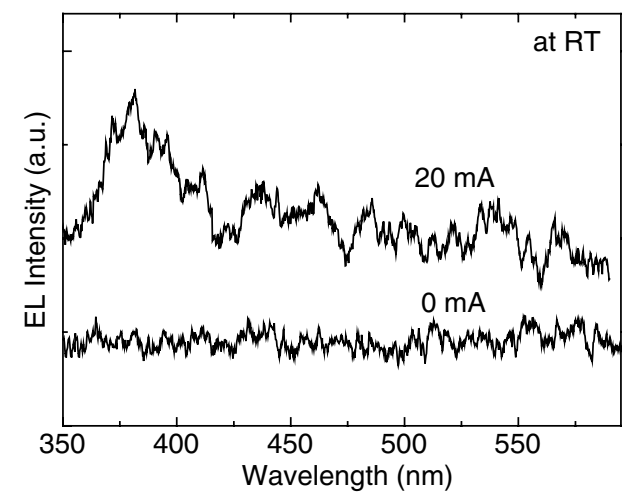

Figure 5. A room-temperature EL spectrum of $\mathrm{ZnO}$ homojunction LEDs.

the $\mathrm{N}_{\mathrm{O}}$ acceptor. In addition, an acceptor energy level located at $170-200 \mathrm{meV}$ above the VBM is obtained, assuming that the $3.236 \mathrm{eV}$ emission is a DAP transition [8]. This value agrees fairly well with those reported for $\mathrm{N}$-doped $\mathrm{ZnO}$, such as $165 \mathrm{meV}$ [31] and $180 \mathrm{meV}$ [32].

Finally, $\mathrm{ZnO}$ homojunction LEDs were fabricated by the deposition of a N-doped p-type layer on an n-type bulk $\mathrm{ZnO}$ substrate. Au and In-Zn alloys were used as the ohmic contact electrodes for the $\mathrm{p}$ side and the $\mathrm{n}$ side, respectively, showing linear $I-V$ characteristics indicative of good ohmic behaviour (data not shown). Figure 4 shows the $I-V$ characteristics of the $\mathrm{ZnO}$ homojunction. The device exhibits rectification for the repeated measurements, which is consistent with the formation of a $\mathrm{p}-\mathrm{n}$ homojunction at the interface. Note that the quasilinear $I-V$ characteristics at the larger forward bias might be associated with the series resistance of the bulk $\mathrm{ZnO}$ substrate.

Figure 5 demonstrates a room-temperature EL spectrum of $\mathrm{ZnO}$ homojunction LEDs. At a current of $20 \mathrm{~mA}$, a UV peak centred at $379 \mathrm{~nm}$ dominates the EL spectrum, which could be ascribed to exciton-related emission. It is believed that the UV emission comes from the electron injection from n-type bulk $\mathrm{ZnO}$ to the p-type layer, because the electron mobility of the bulk $\mathrm{ZnO}\left(\sim 100 \mathrm{~cm}^{2} \mathrm{~V}^{-1} \mathrm{~s}^{-1}\right)$ is much larger than the hole mobility of the p-type layer. In addition, the intensity ratio of the exciton emission to the deep band is higher than the previous reports on $\mathrm{ZnO}$ homojunction 
$[17,18,21-24]$, including that grown by a complicated plasmaassisted process.

\section{Conclusion}

In summary, we have developed a plasma-free MOCVD method to grow reproducible $\mathrm{N}$-doped p-type $\mathrm{ZnO}$ films. The incorporated $\mathrm{N}$ acceptor, as identified by XPS, will effectively lower the Fermi level towards the VBM and is responsible for p-type conductivity. The observations of obvious acceptorrelated $\mathrm{PL}$ transitions, such as $\mathrm{A}^{\circ} \mathrm{X}$ and probably DAP, indicate the presence of an acceptor state in the $\mathrm{N}$-doped $\mathrm{ZnO}$. In addition, typical rectifying $I-V$ characteristics and roomtemperature EL from the $\mathrm{ZnOLEDs}$ are demonstrated, which is comparable to or even better than those grown by a complicated plasma-assisted process. Our results suggest that the plasmafree $\mathrm{N}$ doping would be a promising way to produce stable p-type $\mathrm{ZnO}$.

\section{Acknowledgments}

This work was supported by the National Basic Research Program of China under Grant No 2006CB604906 and the National Natural Science Foundation of China under Contract Nos 50532060 and 90601003.

\section{References}

[1] Look D C 2001 Mater. Sci. Eng. B 80383

[2] Pearton S J, Norton D P, Ip K, Heo Y W and Steiner T 2005 Prog. Mater. Sci. 50293

[3] Özgür Ü, Alivov Ya I, Liu C, Teke A, Reshchikov M A, Doğan S, Avrutin V, Cho S J and Morkocd H 2005 J. Appl. Phys. 98041301

[4] Van de Walle C G 2000 Phys. Rev. Lett. 851012

[5] Cox S F J et al 2001 Phys. Rev. Lett. 862601

[6] Kohan A F, Ceder G, Morgan D and Van de Walle C G 2000 Phys. Rev. B 6115019

[7] Zhang S B, Wei S H and Zunger A 2001 Phys. Rev. B 63075205

[8] Look D C, Reynolds D C, Litton C W, Jones R L, Eason D B and Cantwell G 2002 Appl. Phys. Lett. 811830

[9] Rommeluere J F, Svob L, Jomard F, Mimila-Arroyo J, Lusson A, Sallet V and Marfaing Y 2003 Appl. Phys. Lett. 83287
[10] Zeng Y J, Ye Z Z, Xu W Z, Liu B, Che Y, Zhu L P and Zhao B H 2007 Mater. Lett. 6141

[11] Lim J H, Kang C K, Kim K K, Park I K, Hwang D K and Park S J 2006 Adv. Mater. 182720

[12] Heo Y W, Kwon Y W, Li Y, Pearton S J and Norton D P 2004 Appl. Phys. Lett. 843474

[13] Vaithianathan V, Lee B T and Kim S S 2005 Appl. Phys. Lett. 86062101

[14] Guo W, Allenic A, Chen Y B, Pan X Q, Che Y, Hu Z D and Liu B 2007 Appl. Phys. Lett. 90242108

[15] Zeng Y J, Ye Z Z, Xu W Z, Li D Y, Lu J G, Zhu L P and Zhao B H 2006 Appl. Phys. Lett. 88062107

[16] Zeng Y J, Ye Z Z, Lu J G, Xu W Z, Zhu L P, Zhao B H and Limpijumnong S 2006 Appl. Phys. Lett. 89042106

[17] Tsukazaki A et al 2005 Nature Mater. 442

[18] Xu W Z, Ye Z Z, Zeng Y J, Zhu L P, Zhao B H, Jiang L, Lu J G, He H P and Zhang S B 2006 Appl. Phys. Lett. 88173506

[19] Nause J, Pan M, Rengarajan V, Nemeth W, Ganesan S, Payne A, Li N and Ferguson I 2005 Proc. SPIE 5941 59410D

[20] Ryu Y, Lee T S, Lubguban J A, White H W, Kim B J, Park Y S and Youn C J 2006 Appl. Phys. Lett. 88241108

[21] Wang H T, Kang B S, Chen J J, Anderson T, Jang S, Ren F, Kim H S, Li Y J, Norton D P and Pearton S J 2006 Appl. Phys. Lett. 88102107

[22] Liu W et al 2006 Appl. Phys. Lett. 88092101

[23] Sun J C, Zhao J Z, Liang H W, Bian J M, Hu L Z, Zhang H Q, Liang X P, Liu W F and Du G T 2007 Appl. Phys. Lett. 90121128

[24] Adekore B T, Pierce J M, Davis R F, Barlage D W and Muth J F 2007 J. Appl. Phys. 102024908

[25] Wei Z P, Lu Y M, Shen D Z, Zhang Z Z, Yao B, Li B H, Zhang J Y, Zhao D X, Fan X W and Tang Z K 2007 Appl. Phys. Lett. 90042113

[26] Yan Y F, Zhang S B and Pantelides S T 2001 Phys. Rev. Lett. 865723

[27] Maki H, Sakaguchi I, Ohashi N, Sekiguchi S, Haneda H, Tanaka J and Ichinose N 2003 Japan. J. Appl. Phys. 4275

[28] Girard R T, Tjernberg O, Chiaia G, Soderholm S, Karlsson U O, Wigren C, Nylen H and Lindau I 1997 Surf. Sci. 373409

[29] Perkins C L, Lee S H, Li X N, Asher S E and Coutts T J 2005 J. Appl. Phys. 97034907

[30] Meyer B K et al 2004 Phys. Status Solidi b 241231

[31] Zeuner A, Alves H, Hofmann D M, Meyer B K, Hoffmann A, Haboeck U, Strassburg M and Dworzak M 2002 Phys. Status Solidi b 234 R7

[32] Zeng Y J, Ye Z Z, Lu Y F, Lu J G, Xu W Z, Zhu L P and Zhao B H 2007 J. Phys. D: Appl. Phys. 401807 